\title{
Enhancement of Mechanical Engineering Degree through student design competition as added value. Considerations and viability.
}

Ana de-Juan, *Alfonso Fernández del Rincón, Miguel Iglesias, Pablo García, Alberto Diez-Ibarbia, Fernando Viadero

Department of Structural and Mechanical Engineering. University of Cantabria. Santander.SPAIN.dejuanam@unican.es; fernandra@unican.es; iglesiassm@unican.es; garciafp@unican.es; diezia@unican.es; viaderof@unican.es

* Alfonso Fernández del Rincón. Department of Structural and Mechanical Engineering. University of Cantabria. Avda. De los Castros s/n, 39005 Santander SPAIN. fernandra@unican.es Tel: +34942200936. Fax: +34942201853.

Acknowledgments: The authors would like to acknowledge Project DPI2013-44860 funded by the Spanish Ministry of Science and Technology and Vicerrector Primero y de Profesorado of the University of Cantabria for supporting this research. 


\title{
Enhancement of Mechanical Engineering Degree through student design competition as added value. Considerations and viability.
}

\author{
This paper propose using a student design competition as an learning tool in the \\ Mechanical Engineering Degree for enhancing the general competences and \\ motivation of the students, transferring theoretical knowledge to practical \\ situations and bringing together all courses involved under a common framework. \\ This constitutes an added value that the in-person universities should offer to \\ their students as a consequence of the Bologna process and the raising of open \\ online resources for self-learning.
}

In order to assess the viability of this proposal, a pilot Competition-DesignActivity (CDA) is presented using project-based learning methods during a Mechanism Theory course for sophomore students. Meanwhile, twenty seven participants of a forty five-student course from a European university took part in the pilot CDA, which consisted on redesigning the motorbike rear suspension used in a student design competition. Participants also completed mid-term and final exams as well as a survey to get their perception of this activity.

Based on the success of the pilot CDA, the authors are planning to implement the proposal, including similar CDAs in other Mechanical Engineering courses to use the competition as a link between them and to encourage students to participate on the competition.

Keywords: Mechanical Engineering, Project Based Learning, Student design Competitions, European High Educational Area, open educational resources.

\section{Introduction}

In the past fifteen years, the European Universities have had to adapt their higher education programmes to the Bologna Declaration (European Ministers of Education, 1999), which claimed for the creation of a European High Educational Area (EHEA) "in order to establish the European Area of Higher Education and to promote the European system of higher education world-wide". Among other particular goals, the Bologna Declaration poses the promotion of mobility for both students and staff. One of the tools 
projected to reach this goal is the definition of a credit system, the European Credit Transfer System (ECTS). ECTS is compatible with the European Qualifications Framework for a lifelong learning, because both are based on the workload that a student needs to employ in order to achieve the expected learning outcomes or competences (European Commission, 2009). This is precisely the main change introduced by the EHEA: higher education has to be learning-oriented, rather than the traditional teaching-oriented former model.

With this shift of paradigm, the student is expected to know, understand and be able to do what he has learnt by the end of the process. Within this educational framework, the terms "competences" or "learning outcomes" can be understood as the capacity to transfer knowledge into practice. At the end of their academic programme, students are supposed to have acquired some competences at a specific level, i. e. learning outcomes (OECD, 2011), depending on their specialisation. Competences can be divided in two main groups: general and specific. General competences are common to all academic programmes, i. e. competences related to team work, communication skills, lifelong learning... Specific competences are related to a particular field (Mechanical, Electrical, Civil...). Both general and specific competences must be acquired by students in the different courses that compose the whole academic programme. It can be seen a shared common approach between Europe and the United States of America in the field of Engineering Education with the Engineering Criteria 2000 (EC2000) (Prados et al., 2005) developed by ABET, which highlights the program objectives and learning outcomes. In this regard, it must be taken into account that while specific competences are relatively easy to develop within the different specialized courses, general competences are cross-curricular and more difficult to work 
up given the compartmentalized nature of the different courses composing an academic degree.

Together with this politically imposed change, higher education institutions are progressively facing another important challenge: the open educational resources (Gil et al., 2012). Together with the fact that traditional lecture-based curriculum normally results in low student motivation, retention and autonomy among others; it could come one day in which all educational resources are online (Martin, 2012). Nowadays, an individual who is interested in learning a specific subject could openly access to multimedia materials developed by the most prominent experts in their field. There are currently different works in this direction, for instance, in 2002 the Massachusetts Technical Institute launched Open Course Ware (OCW) (Lerman \& Potts, 2006), a site which contains free access to their courses. OCW has been spread out all over the world and many universities have developed their own similar site (Lee et al., 2007; Vlădoiu, 2011). Actually, the open educational resources are an available tool for learning oriented system, because this can improve students' motivation, as well as their competences and learning outcomes (Carson et al., 2012), so their use by all kind of educational institutions is completely recommended. Within this background, what will be the role of in-person universities in this envisaged situation? What do the universities have to offer to attract students? Obviously the key answer to this question is the added value that in-person universities can provide: a learning framework capable of improving the motivation and autonomy of the students.

Following this line of thought, authors believe that student design competitions, such as Formula SAE series (2015), Shell eco-marathon (2015), RoboCup (2015), MotoStudent (2015), are an exceptional framework to integrate the learning oriented education and to foster students' motivation. In these kinds of competitions, students 
can apply their classroom knowledge to a real situation, to acquire general competences (team work, communication skills, etc.) and to learn how to face problems they might encounter during their careers.

Previous research works show the usefulness of these kinds of competitions as a combination between learning and research (Labossìre \& Bisby, 2010) and its educational value (Al-Marzouqi \& El-Naas, 2012; Davies, 2013a; Davies, 2013b). For instance, Post \& Lee (2011) present their experience at the University Rover Challenge, stating that participating students gained in both 'hard' engineering skills (similar to what we are already defined as specific competences) and 'soft' skills (general competences). The latest ones are more difficult for students to be learned in the ordinary classroom. Battisti et al. (2011) developed a team student competition in a course of digital information security. Students that took part on it graded higher than the others and found it motivating. Ahlgren \& Verner (2013) uses also a robot design competition to show the students some applications that can be very useful to elderly and disabled people.

In addition to all the reasons given in the previous paragraphs, the authors in this work realized that an unexploited possibility related with student design competitions remained. This is the possibility of bringing together all the courses in a degree under a common framework, linking knowledge of different courses through practical and real problems, and tackling one of the main problems of many degrees and engineering schools: although the courses should be intertwined and connected, they are taught like isolated subjects.

Thus, the authors decided to introduce a student design competition into the Mechanical Engineering Degree step by step by means of the different courses. This is done by including some Competition-Design-Activities (CDA) within the courses 
related to the specific tasks that should be accomplished in the competition, according to the knowledge taught in each course as shown in Figure 1. Thus, the student design competition will be integrated in a natural way into the Mechanical Engineering Degree and will constitute an additional part of it.

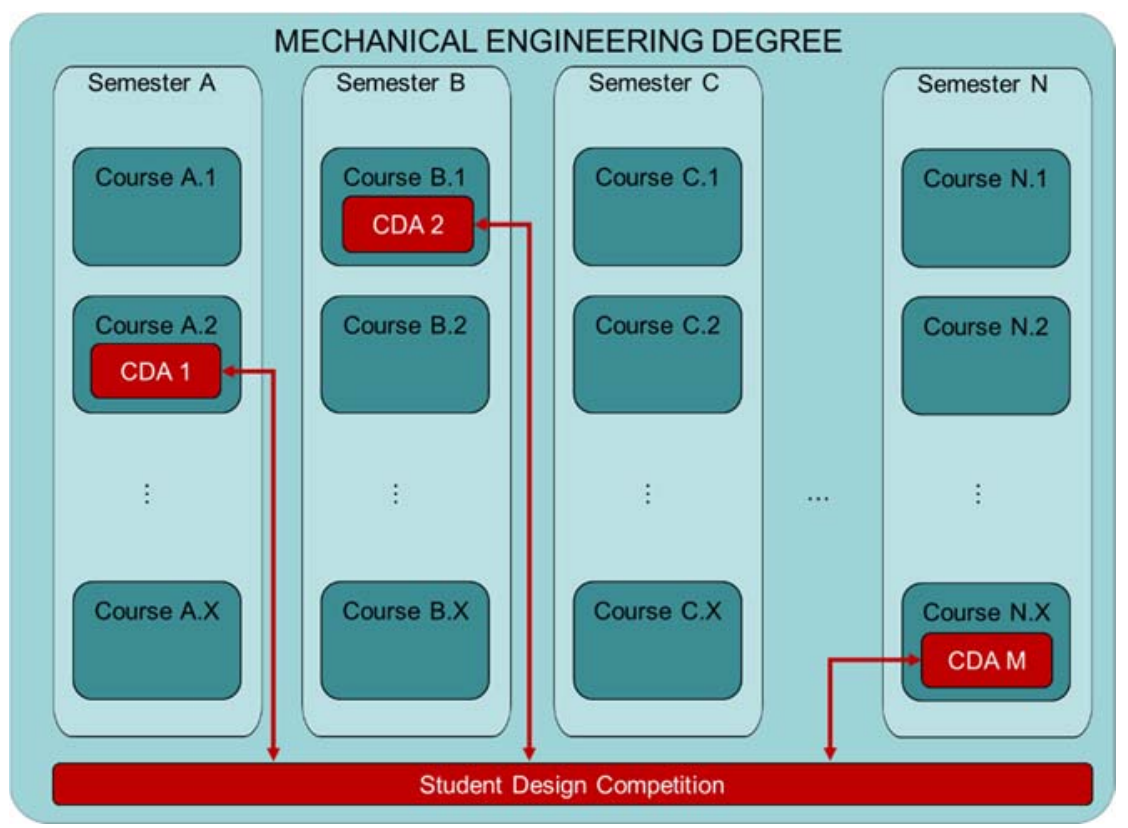

Figure 1: Introduction of activities within the courses of a Mechanical Engineering degree using a student design competition as a common framework.

This is a meta-idea that constitutes the framework of this paper. Authors, who are the instructors of the courses, try to use this competition with different educational medium-term Meta-Objectives (MO):

- MO1: To transfer theoretical knowledge to real situations: The competition not only implies 'to do the math', but to apply their acquired knowledge to make the best solution.

- MO2: To improve students' general competences: Students are expected to work within a multidisciplinary team, to accomplish a real schedule, and to express themselves properly in different situations (not only among equals but also with 
the rest of stakeholders outside the university, e.g. to obtain sponsors) and to cope with inner conflicts.

- MO3: To increase students' motivation: Working on real problems is always more appealing than theoretical situations. Also, a student design competition is always a motivating challenge for participants.

- MO4: To establish a link between different courses. Students usually have the idea that these courses, which compose a whole academic programme, are detached from each other. The main idea is to combine knowledge from different subjects to a common goal.

These educational meta-objectives are ambitious and of medium-term duration. In order to assess the viability of carrying out this meta-idea, authors decided to develop one pilot CDA, which is described in the next sections. If this pilot CDA shows to be worthy, similar actions will be taken within other courses of the Degree, fully integrating the meta-idea in a few academic years.

Section 2 provides the background of the authors in the student design competition, where the meta-idea comes from, and some previous practices of successful application of learning oriented methods to engineering courses. In Section 3 the method for the pilot CDA is described emphasizing the kinds of participants, procedure and materials involved. Section 4 shows the results of the pilot CDA, in Section 5 all the findings and shortcomings are discussed and, finally, in Section 6 the main conclusions and future research are described. Besides, two annexes with the statement of the pilot CDA and the rubric are attached at the end of this paper. 


\section{Background}

\subsection{Experience on student design competitions}

At a European level, there are some student design competitions for student teams.

Although the final goal for these competitions may be different, all of them present an exceptional opportunity for students to apply their classroom knowledge to a real situation, and to start facing problems they will encounter during their careers.

For instance, Formula SAE (2015) is a competition for student teams, which was born at US. It has also been spread to other countries, such as Italy, UK and Germany. The goal for the teams is to build a small race car which is assessed for its suitability for competition and for production item.

Shell Eco-Marathon (2015) goal is to promote the sustainable mobility among young engineers. The teams try to build the most efficient car from the point of view of the fuel consumption.

MotoStudent (2015) is an international competition where the university teams must design and build a $250 \mathrm{cc}$. race motorbike and present a manufacturing plan in order to build 600 units per year of the prototype. The maximum manufacturing cost is limited to $4750 €$ per unit.

Apart from automotive competitions, there are others such as RoboCup (2015) series which are a robotics and artificial intelligence contests. Although there are different categories, its initial target was to build robots that can actually play soccer.

Authors have experience on participating in the MotoStudent competition. The students that composed the team come from different Engineering Degrees, such as Mechanical, Electronical and Telecommunications. According to the technical rules, organization provided the engine, front and rear suspension and wheels. The team mainly had to design and verify the chassis and the swinging arm, build a prototype and 
then define the industrial process to build 500 units. After about eighteen months the team eventually built the motorbike prototype and took part into the competition. They had a good mark in the definition of the industrial process, but due to technical problems they failed in the circuit test. Despite this fact, they ranked in the middle section of the chart in the global classification.

After the competition, the team and the tutors analysed their strong and weak points, trying to take advantage of their experience for future teams. One of the main weak points was the reduced number of students involved in the team. One issue they agreed on was other participant' teams had double number of members than ours. The problem was that the students must be up to their third year because the competition lasts three semesters. However, students found the experience very motivating and positive, and despite the great effort they made to complete the motorbike, they really think it was worth it because they learnt how to apply their knowledge to a real situation and to deal with non-technical problems. Thus, the team members realized they had achieved the mid-term educational meta-objectives described in section 1, especially the first three of them (MO1-MO3).

With this background, authors decided to use the MotoStudent competition as a learning tool for all the students in the degree, introducing competition design activities in the different courses, as shown in Figure 1. Within this framework, a pilot CDA was set in a Mechanism Science course of the Degree in order to assess the viability of developing the meta-idea in the whole Degree. In this pilot CDA, where Project-Based Learning method (PjBL) was used, students were asked to redesign the rear suspension system of the original motorbike prototype that took part in the competition to improve its behaviour. The selection of this method for the pilot CDA is justified in the next subsection. 


\subsection{Learning-based method: PjBL}

Jonassen, et al. (2006) identify the characteristics of the problems that engineers have to face during their whole professional life. They are usually ill-structured, can be solved by different approaches, have additional non-engineering constraints and conflicting goals, must be solved by a team whose members have different background... These authors termed this as "workplace problems". However, these problems are different from "traditional (or classroom) problems", which are stated with an initial statement that leads to a specific solution through (usually) a mathematical procedure. The transference between classroom and workplace problems is not always so clear. For this reason, they suggest to include some learning-based methods in the engineering programs.

There are a large variety of teaching and learning methods used in Engineering Education. $\mathrm{PjBL}$ and Problem-Based Learning $(\mathrm{PbBL})$ as well as Case-Based Teaching (CBT) methods are some examples of them and have been successfully applied with this end. However, these methods present some similarities that make difficult to clearly differentiate them, as Prince \& Felder (2006) stated. In that paper, authors defined and assessed these and others inductive learning methods through a review of experiences that have been already carried to practice. For instance in CBT, students deal with real or hypothetical situations involving challenges. Sometimes the solution that was presented to solve the challenges is even given to students and they must assess it, giving other possible ways of acting. In this paper, authors stated $\mathrm{PjBL}$ "begins with an assignment to carry out one or more tasks that lead to the production of a final product... The culmination of the project is normally a written and/or oral report summarizing the procedure used to produce the product and presenting the outcome." 
With respect to comparison to $\mathrm{PbBL}$, authors present some similar aspects, e. g. they "usually involve teams of students in open-ended assignments". However, the main difference is the intrinsic objective of each procedure: while $\mathrm{PbBL}$ is aimed to gaining new knowledge, in the $\mathrm{PjBL}$ the goal is to apply or integrate the previous knowledge. Nevertheless, as these authors recognise, this difference in practice is not always clear, and each experience is different and sometimes could be grouped by more than one inductive teaching and learning method.

Despite the fact that these methods are widely used, there are a few studies that empirically assess the learning outcomes rather than focus on students' perception. These studies show that these techniques, PbBL, PjBL and CBT have not negative effects on students' knowledge and development of skills. Yadav et al. (2010) implemented two CBT experiences about thermal and fluid mechanics in two classes of a Mechanical Engineering Course. This paper shows that, despite the students show a positive attitude toward the cases, they felt that they did cover less content than with the traditional lecture lessons. The empirical results show that students' conceptual understanding did not improve significantly with this method, although their motivation for learning were increased. These authors stated that case studies are useful, but they must be introduced gradually to both give some time to students' adaptation to this technique and to understand its purpose. Yadav et al. (2011) combined traditional lectures with $\mathrm{PbBL}$ in an Electrical Engineering course. This enables these authors to assess the conceptual understanding of the students from the PbBL in comparison with traditional lectures. From the empirical objective results, they obtain that with $\mathrm{PbBL}$ students learning gains are twice higher than with traditional lecture. However, students' subjective impressions, measured through a survey, are the opposite. Galand et al. (2012) stress two important issues: on one hand, they distinguish three levels of 
knowledge, namely, understanding of concepts, understanding of principles and application of concepts and principles. They conclude that the $\mathrm{PbBL}$ and $\mathrm{PjBL}$ curriculums enhance the third level, and do not show any detriment in the other two levels. On the other hand, they demonstrate that the effectiveness of these techniques depends also on the education context based on their own experience on medical and engineering education.

General competences can be also improved with these learning-based methods. For instance, Giralt, et al. (2000) show a procedure which involved students of first and fourth year in a common project leaded by the latter, which also includes professors, industry participants and authorities. This enables students to be integrated from the very beginning in an engineering team work and to deal with the several issues that this implies. Moreover, these authors show that the grades of students who participated in this work were improved. Maseda et al. (2012) developed a training tool, and the methodology for working with it, which improve both motivation and technical skills of engineering students about experimental work. The training tool was designed in terms of modular blocks and students have improved it during projects and master thesis, so it can be used for students during their whole academic programme in different courses. Thus, the tool is enhanced by a multidisciplinary group of students with the same common goal.

Despite all these advantages, learning based approaches we have mentioned have an important drawback from the students' point of view compared to traditional lecture-based teaching (LBT) methods: the workload. It is important to highlight that the whole academic program is composed by a number of individual courses. If students have to work in problems and projects in each particular course, they will expend a considerable higher amount of time than if they are assessed only with final exams. A 
study carried out by Nepal (2013) shows that, despite the fact that students' perception about benefits of a combination of PbBL and PjBL is upper than LBT, they would rather the latter because of workload in author's opinion. This fact even reinforces the authors' meta-idea of integrating the student design competition into the Degree by means of introducing a specific CDA in each course related to the competition. As stated in the previous section, if the student design competition is used as a link between courses, students will have to face different parts of the whole design of the motorbike in each course, but they will already be familiar with the main problem. In our opinion this is a way of saving time for students, rather than if we present them different unconnected activities during their academic program.

We chose to use PjBL for the pilot CDA because two main reasons: (a) students must apply their acquired knowledge to solve a specific problem, in order to improve the transition between classroom and work place problems, as Prince \& Felder (2006) encourage and (b) PjBL sets an ideal opportunity for developing the competences (skills), both general ('soft') and specific ('hard'), which the students must acquire in the course. Although LBT can create the appropriate atmosphere to develop specific competences, we think that this is not enough for general competences. This is one of the reasons why it is necessary to include learning-based methods. For instance, using PjBL has demonstrated to enhance general competences such as oral and written communication, creative thinking and team work (Jimenez, 2015). Stolk (2015) uses $\mathrm{PjBL}$ to integrate social sciences in an engineering materials science course. His findings show an improvement of students' critical thinking as well as boosting in motivation and self-regulated learning strategies. Tao (2015) arises the same conclusion in a different scenario: a course for electrical engineers. 
Taking into account of all the above, the Pilot CDA Objectives (PCDAO) are listed next:

- PCDAO 1: To face ill-structured problems, which are close to reality. This can be seen as an additional motivation because it is not just "to do the math".

- PCDAO 2: To encourage them to participate in student competitions. This can stimulate their creativity by applying their specific knowledge.

- PCDAO 3: To be able to identify and distinguish different possibilities of rear suspension designs.

- PCDAO 4: To improve their skills on searching information, technical vocabulary and collaborative work.

Reader should note that these PCDAO 1-4 contribute to the achievement of the MO1-3, as can be seen on Figure 2. Also, the pilot CDA itself contributes to the achievement of MO4, when other CDAs are implemented within the Degree.

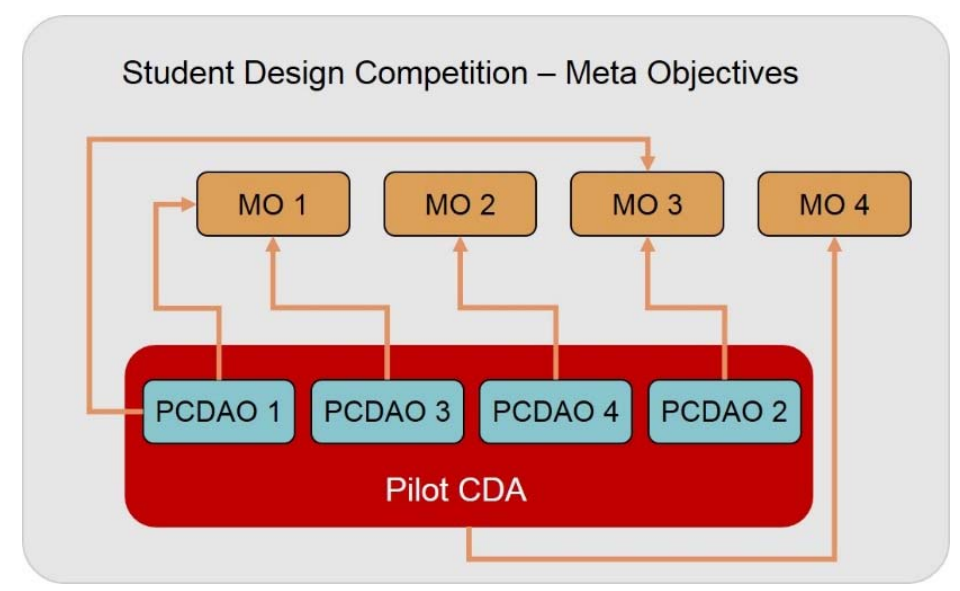

Figure 2: Contribution of the PCDAO to the achievement of the MOs.

\section{Method of the pilot CDA}

\subsection{Course description and participants}

The course where the pilot CDA was developed belongs to an academic programme in 
Mechanical Engineering of a European University, with fifteen weeks of duration. This course provides an overview of the multi-body kinematics, both analysis and synthesis, including linkages, cams and gears. This is done by means of traditional lectures, classroom problems and laboratory activities. Students were also trained to use commercial multibody system software. An online course management system was available for students during the course, where they could find all the material required for lessons, as well as former exams and additional readings.

As part of integration into the EHEA, all courses that belong to official academic programmes must specify the competences and learning outcomes for the students. Table 1 shows this information, taking into account that competences are divided into general and specific, as it was explained in section 1.

Table 1: Competences and Learning Outcomes of the course

\begin{tabular}{|c|c|c|}
\hline \multicolumn{3}{|c|}{ Competences } \\
\hline & Code & Description \\
\hline \multirow[t]{5}{*}{ General } & GC1 & $\begin{array}{l}\text { To obtain the knowledge in basic and technologic subjects, enabling for the } \\
\text { learning of new methods and theories and providing adaptability to get used to } \\
\text { new situations. }\end{array}$ \\
\hline & GC2 & $\begin{array}{l}\text { To obtain the ability of taking the initiative of solving problems, taking } \\
\text { decisions, creativity, critical reasoning, transmit knowledge, skill and dexterity } \\
\text { in the field of Mechanical Engineering. }\end{array}$ \\
\hline & GC3 & Development of critical thinking. \\
\hline & GC4 & To acquire the ability of verbal communication. \\
\hline & GC5 & To acquire the ability of written communication. \\
\hline \multirow[t]{2}{*}{ Specific } & $\mathrm{SC1}$ & $\begin{array}{l}\text { Knowledge and comprehension about the general laws of Mechanics and its } \\
\text { application to solve engineering problems. }\end{array}$ \\
\hline & $\mathrm{SC} 2$ & To get the knowledge of the Mechanism and Machine Theory basics. \\
\hline \multicolumn{3}{|c|}{ Learning outcomes } \\
\hline & Code & Description \\
\hline & LO1 & $\begin{array}{l}\text { The student must be able to comprehend the Machine Theory basics and its } \\
\text { application. This will give him the ability to face more specific courses and to } \\
\text { develop their professional activity. }\end{array}$ \\
\hline & $\mathrm{LO} 2$ & $\begin{array}{l}\text { The student will be able to analyse and comprehend how the general } \\
\text { mechanical systems work. }\end{array}$ \\
\hline & LO3 & $\begin{array}{l}\text { The student will be prepared to define the basic kinematic design requirements } \\
\text { of a mechanism and to develop a dimensional synthesis. }\end{array}$ \\
\hline
\end{tabular}

Students must acquire the competences and learning outcomes from Table 1 in order to pass this course. In the traditional teaching-oriented former model of education 
previous to Bologna's, only specific competences and learning outcomes were considered and developed in the courses. The student had 'just' to learn some technical concepts and apply them to solve specific problems. However, the new education model demands to work also on general competences, and it is exactly at this point where the pilot CDA fits. Taking a look at the competences labelled from GC1 to GC5, it is obvious that the pilot $\mathrm{CDA}$ using PjBL provides a perfect framework to develop these general competences as well as the specific ones due to the characteristics of $\mathrm{PjBL}$ that have been described in section 2.2. However, as it was stated by Woods (1996), in order to really work on these general competences, they have to be evaluated 'because students learn what is being assessed'. The evaluation process will be detailed in section 3.4.

Additionally to the regular course actions (lectures and classroom and lab problems), the pilot CDA was presented to the forty five students who were enrolled in the course. As the pilot CDA was eligible, twenty-seven followed it initially, where four were females and twenty three were males. These participants worked in randomized groups of three students each initially.

\subsection{Materials}

Two kinds of materials were given to students in order to complete the pilot CDA, namely, (i) statement of work, where the aims and the desired output of the pilot CDA were defined and (ii) a survey to be filled in at the end of the course to obtain the subjective perception of participants about the pilot CDA. Information included on both materials is described next.

The statement of work, which can be found on Annex 1, described the general aim, the expected learning outcomes and competences which were supposed to be developed during the pilot CDA. As can be seen, although all general competences from 
Table 1 could be assessed using the pilot CDA, only GC3, GC4 and GC5 are explicitly developed and therefore assessed. Participants were asked to deliver a report (GC5, from Table 1), covering some common points and to make an oral public presentation (GC4, from Table 1) of the results. The pilot CDA aimed to redesign a rear suspension system of a race motorbike. Participants had to take the actual design of the motorbike that took part on MotoStudent competition as starting point of their work. They were provided in the statement of work with technical drawings of this motorbike including topology and dimensions. Therefore, participants should present not only the best mechanism but also the optimal function for the behaviour of the suspension system. This kind of problem is very usual in engineering design, because designers normally know the procedures of how to obtain something that fulfils a particular set of specifications. The actual challenging problem is usually to define those specifications, and this was one of the goals of this work, to define and bind the problem itself, i. e. students must develop their critical thinking (GC3, from Table 1). .

In order to assess the perception of the students about the pilot CDA, they were asked to fill in a survey. This was completely anonymous for participants and was done in an online course management system. This survey consisted on twenty three items that were valued according to Table 2 .

Table 2: Scale for the survey items.

\begin{tabular}{|l|c|}
\hline \multicolumn{1}{|c|}{ Description } & Value \\
\hline Totally disagree & 0 \\
\hline Strongly disagree & 1 \\
\hline Disagree & 2 \\
\hline Agree & 3 \\
\hline Strongly agree & 4 \\
\hline Totally agree & 5 \\
\hline
\end{tabular}


Items were grouped in the next five sets:

- Activity: Participants give their general opinion about the pilot CDA and the achievement of its aims.

- Learning: Participants give their opinion about their perception of learning from the pilot CDA.

- Dedication: Participants assess the hours they have spent on the pilot CDA.

- Work group: Participants assess their work group in terms of satisfaction.

- Competences: Participants assess their academic programme of achievement of the desired competences.

Table 3 shows the items of the survey grouped by sets. Note that last item (No. 23 ) is intended to collect commentaries from participants, so it is not attached to any set.

\subsection{Procedure}

The pilot CDA was embed in the regular course actions, as Figure 3 shows, which represent the distribution of topics (developed by means of traditional lectures and classroom problems), laboratory and pilot CDA activities that were carried out during the fifteen weeks of the course. The topics were:

- T1: Introduction to Mechanisms Science, where students learn to identify the elements and joints of actual mechanisms.

- T2: Introduces the Planar Motion of Mechanism, where students learn to analyse a mechanism by means of relative motion among its components, i. e. what is the functionality of each specific mechanism. 
- T3: This topic gives the guidelines of Mechanism Synthesis. From design requirements, students learn to design the mechanism in order to obtain a required functionality.

- T4: Analysis and design of Cams

- T5: Analysis and design of Gears

Note that students were asked to redesign the suspension system of the motorbike, which neither included cams nor gears. For this reason, on week 10 the students had been taught all the necessary knowledge to face the problem.

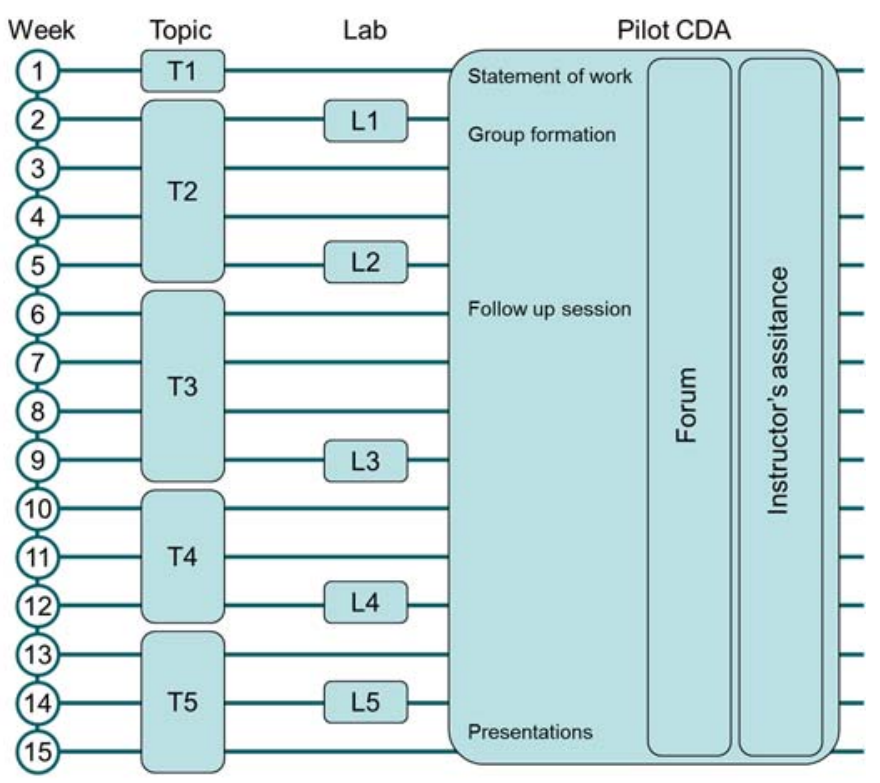

Figure 3: Distribution of topics of the course, lab activities and pilot CDA items during fifteen weeks

During the course, all documentation of the pilot CDA as well as a forum where students could exchange opinions and information were also available on the online course management system. Moreover, the groups were tutored by an instructor to give them a more personal guidance.

At the beginning of the course, on week 1, the pilot CDA was announced to all students of the course. Both the aims and grading of the pilot CDA were outlined in 
order to give the students the chance to participate or not. Statement of work was available on the online course management system. Two weeks later, on week 3, groups were formed among twenty-seven initial participants.

On week 6, a control session was developed in order to bring all the questions and doubts together. All groups were asked to perform a brief presentation about the work they had already developed and the envisaged work to come. Moreover, four participants from the initial twenty-seven withdrew from the pilot CDA before this session. This fact forced the instructors to reset the working groups, and one of them was composed only by two students.

Finally, on week fifteen, groups had to deliver the report and to perform a ten minutes length presentation, in which they explained their final design and answered questions asked by instructors and other participants. After week fifteen, the final test of the course and the survey were carried out.

\subsection{Course assessment}

The pilot CDA was presented as an optional work that composed the $20 \%$ of the total course grade. Students that chose not to do the pilot CDA could obtain only up to $80 \%$ of the total course grade. In order to pass the course, students must have at least $50 \%$. Thus, traditional lectures, classroom problems and lab activities were the $80 \%$ of the grade. The knowledge achieved by students (SC1 and SC2 in Table 1) was assessed by means of two exams, namely mid-term test and final test, each of them graded $40 \%$ of the total final mark. Each of these tests were composed by a multiple choice set of questions, one subject to be briefly developed about lab activities and two classroom problems that were similar to the ones developed at the classroom. This was the first time that this course was adapted to the EHEA requirements. In the previous editions of this course, the assessment was done uniquely by means of one final exam at the end of 
the semester.

There is not a unique technique for assessment in PjBL (Woods, 1996). It can be focused on measuring student's development during learning process, student's learning and conceptual understanding of the topic (Yadav, 2011), or specific competences (Zhou, 2013). The assessment technique mainly depends on how the PjBL is implemented within the course and the goals that are meant to be achieved with it (Bin Masek, 2010). Regardless the chosen assessment method in a particular study (multiple choice, essay questions, project rating...), it is important to give the reader enough data to evaluate the validity and reliability of the assessment procedure (Belland, 2009). This means that the framework of the course must be properly described, including materials, students, background and results.

A rubric, which is included in Annex 2, was developed for the benefit of the pilot CDA assessment, where general competences GC3, GC4 and GC5 were evaluated. A scale from 0 to 4 was used, were 0 indicates null and 4 indicates full achievement of results. $10 \%$ was obtained from the report and the rest $10 \%$ from the oral presentation. The rubric covered for both written report and oral presentation the four required sections described in the "statement of work" (see Annex 1) and also clarity in written and oral language. The progress of the group during the weeks was not taken into account. This was because the groups were randomized formed and as some of them had to be reformed, the goal was to not penalize those who had these inconveniences. Instructions for oral presentations stated that each member of the group must present one part of the work and the questions might be asked to each member, who had to be able to respond by their own. This was done in order to avoid "parasite" members that took advantage of the other's work. At the end of the presentation session on week fifteen, participants were also asked to rank the three best presentations. This was done 
for two main reasons: (i) to include the students' opinion about the other teams' work and (ii) to help instructors with the assessment if a discrepancy was given.

\section{Results of the pilot CDA}

The results of this work are divided in two sections in order to be grouped in objective and subjective results. The objective results were assessed by the grade that students got in the pilot CDA and in the total course. The subjective results were obtained by means of the survey that participants filled out at the end of the course to express their perception about the pilot CDA.

\subsection{Grading}

Twenty students passed the mid-term test and twenty two the final one. When we say that they "passed" the test it means that they got at least a mark equal or greater than the half of the maximum. Thus, taking into account both tests and the pilot CDA, twenty two students passed the course at the end of the semester.

Groups that took part within the pilot CDA got marks between 16\% (minimum) and $20 \%$ (maximum) in it. Instructors valued these works positively because both reports and oral presentations reached the level they were expected. Students presented their work clearly structured and with a great technical level, including the definition of the optimal solution, which was one of the main goals of the pilot CDA. Instructors asked questions to all the members of the team during the oral presentations noticing that most of them had collaborated in the work. At the end of some presentations, a discussion was started by other teams because the chosen solutions were different, trying to justify why their solution was better than the others. Instructors did value neither what the best solution was nor the procedure to achieve it. We really wanted to show the students the actual difficulties they have to face when they deal with a 
problem, i. e. to take close the design to the classroom, increasing their critical thinking and design skills and realising that open-ended problems do not have a unique best solution.

In the end, 96\% students that were involved with the pilot CDA passed the course, proving that they actually got the required conceptual understanding of the envisaged knowledge. Students that did not take part in this pilot CDA also did not follow the course and did not take the final exams.

\subsection{Survey}

The survey was done by the twenty three participants in the pilot CDA. Table 3 shows the survey items. The student's perception about the fulfilment of both meta-objectives (MO1-4) and Pilot CDA Objectives (PEO1-4) is assessed in the survey.

Table 3: Survey items

\begin{tabular}{|c|c|c|}
\hline Set & No. & Item \\
\hline \multirow{4}{*}{ 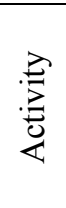 } & 1 & I found this activity motivating \\
\hline & 2 & $\begin{array}{l}\text { Thanks to this activity I am looking forward to participating in other student design } \\
\text { competitions, such as MotoStudent, SAE Formula, EcoShell, RoboCup, ... }\end{array}$ \\
\hline & 3 & This activity could be similar to a real problem. \\
\hline & 4 & This activity has helped me to link different courses within my academic programme. \\
\hline \multirow{5}{*}{ •.્ఠ } & 5 & First time I faced this activity I thought I was not able to solve it. \\
\hline & 6 & In my opinion, the approach of this activity should be applied on other courses. \\
\hline & 7 & $\begin{array}{l}\text { My first impression about the difficulty of this activity changed and now I am aware that I } \\
\text { really have learned. }\end{array}$ \\
\hline & 8 & $\begin{array}{l}\text { Thanks to this activity, I have found useful the knowledge that I have learnt during the } \\
\text { course. }\end{array}$ \\
\hline & 9 & Instructors' help have been very important to carry out this activity. \\
\hline \multirow{2}{*}{ 离 } & 10 & Amount of time (in hours) invested in this activity. \\
\hline & 11 & My participation in this activity has helped me in improving my learning in other courses. \\
\hline \multirow{7}{*}{ 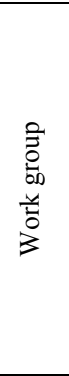 } & 12 & Work group has been satisfactory for me. \\
\hline & 13 & $\begin{array}{l}\text { My group fellows have transmitted to me clearly their ideas by means of appropriated } \\
\text { resources such as draws, texts, graphs... }\end{array}$ \\
\hline & 14 & Each and every of my group fellows have attended to all meetings. \\
\hline & 15 & We have not had any group conflict. \\
\hline & 16 & From my point of view, each and every fellow have worked what was expected of them. \\
\hline & 17 & In my opinion, my group fellows consider my work and contributions to be positive. \\
\hline & 18 & $\begin{array}{l}\text { To share my proposals and suggestions with my group fellows have improved my } \\
\text { communication skills. }\end{array}$ \\
\hline \multirow{3}{*}{ 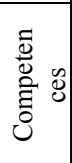 } & 19 & Oral presentation has improved my verbal communication skills. \\
\hline & 20 & $\begin{array}{l}\text { I think that the intended lack of definition of this activity have been beneficial in order to } \\
\text { stimulate my creativity. }\end{array}$ \\
\hline & 21 & I have improved my information search skills. \\
\hline
\end{tabular}




\begin{tabular}{|l|l|l|}
\hline & 22 & $\begin{array}{l}\text { After developing this activity, I feel more confident to face real problems related to this } \\
\text { and other courses. }\end{array}$ \\
\hline & 23 & Anything that I will add, remove or modify about this activity was: \\
\hline
\end{tabular}

Statistical results are shown on Table 4 and in Figure 4 graphically. It is represented the mean value by a colour bar and numerical value and the standard deviation by a thin line.

Table 4: Statistical results of the survey

\begin{tabular}{|c|c|c|c|c|c|c|c|c|c|}
\hline Set & $\begin{array}{l}\mathbf{N} \\
\text { o. }\end{array}$ & $\mathbf{0}^{*}$ & $\mathbf{1}^{*}$ & $2^{*}$ & $3^{*}$ & $4^{*}$ & $5^{*}$ & Mean & Std Dev \\
\hline \multirow{4}{*}{ 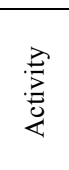 } & 1 & 0 & 0 & 0 & 52.2 & 13 & 34.8 & 3.86 & 0.95 \\
\hline & 2 & 0 & 0 & 8.7 & 30.4 & 30.4 & 30.4 & 3.71 & 1.7 \\
\hline & 3 & 0 & 0 & 0 & 13 & 73.9 & 13 & 4 & 0.55 \\
\hline & 4 & 8.7 & 0 & 4.3 & 43.5 & 43.5 & 0 & 3.14 & 1.10 \\
\hline \multirow{5}{*}{ 离 } & 5 & 0 & 13 & 0 & 8.7 & 43.5 & 34.8 & 3.86 & 1.35 \\
\hline & 6 & 8.7 & 8.7 & 8.7 & 21.7 & 43.5 & 8.7 & 3.7 & 1.38 \\
\hline & 7 & 0 & 0 & 0 & 4.3 & 52.2 & 43.5 & 4.36 & 0.63 \\
\hline & 8 & 0 & 13 & 4.3 & 43.5 & 30.4 & 8.7 & 3.7 & 1.14 \\
\hline & 9 & 4.3 & 0 & 8.7 & 52.2 & 30.4 & 4.3 & 3.14 & 1.17 \\
\hline \multirow{2}{*}{ 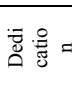 } & 10 & - & - & - & - & - & - & 36.43 & 18.75 \\
\hline & 11 & 8.7 & 4.3 & 43.5 & 34.8 & 8.7 & 0 & 2.29 & 0.99 \\
\hline \multirow{7}{*}{ 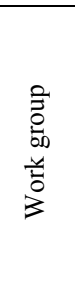 } & 12 & 8.7 & 13 & 0 & 43.5 & 21.7 & 13 & 3 & 1.47 \\
\hline & 13 & 0 & 8.7 & 8.7 & 52.2 & 30.4 & 0 & 3 & 0.88 \\
\hline & 14 & 21.7 & 4.3 & 0 & 21.7 & 21.7 & 30.4 & 3 & 1.96 \\
\hline & 15 & 8.7 & 8.7 & 21.7 & 21.7 & 26.1 & 13 & 3 & 1.47 \\
\hline & 16 & 30.4 & 8.7 & 13 & 8.7 & 30.4 & 8.7 & 2.36 & 1.86 \\
\hline & 17 & 0 & 0 & 0 & 21.7 & 34.8 & 43.5 & 4.21 & 0.80 \\
\hline & 18 & 0 & 0 & 8.7 & 43.5 & 34.8 & 13 & 3.57 & 0.85 \\
\hline \multirow{4}{*}{ 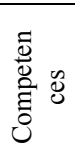 } & 19 & 0 & 0 & 0 & 43.5 & 43.5 & 13 & 3.71 & 0.73 \\
\hline & 20 & 8.7 & 8.7 & 21.7 & 13 & 34.8 & 13 & 3.7 & 1.49 \\
\hline & 21 & 0 & 0 & 0 & 30.4 & 60.9 & 8.7 & 3.79 & 0.58 \\
\hline & 22 & 8.7 & 0 & 0 & 47.8 & 21.7 & 21.7 & 3.43 & 1.28 \\
\hline
\end{tabular}




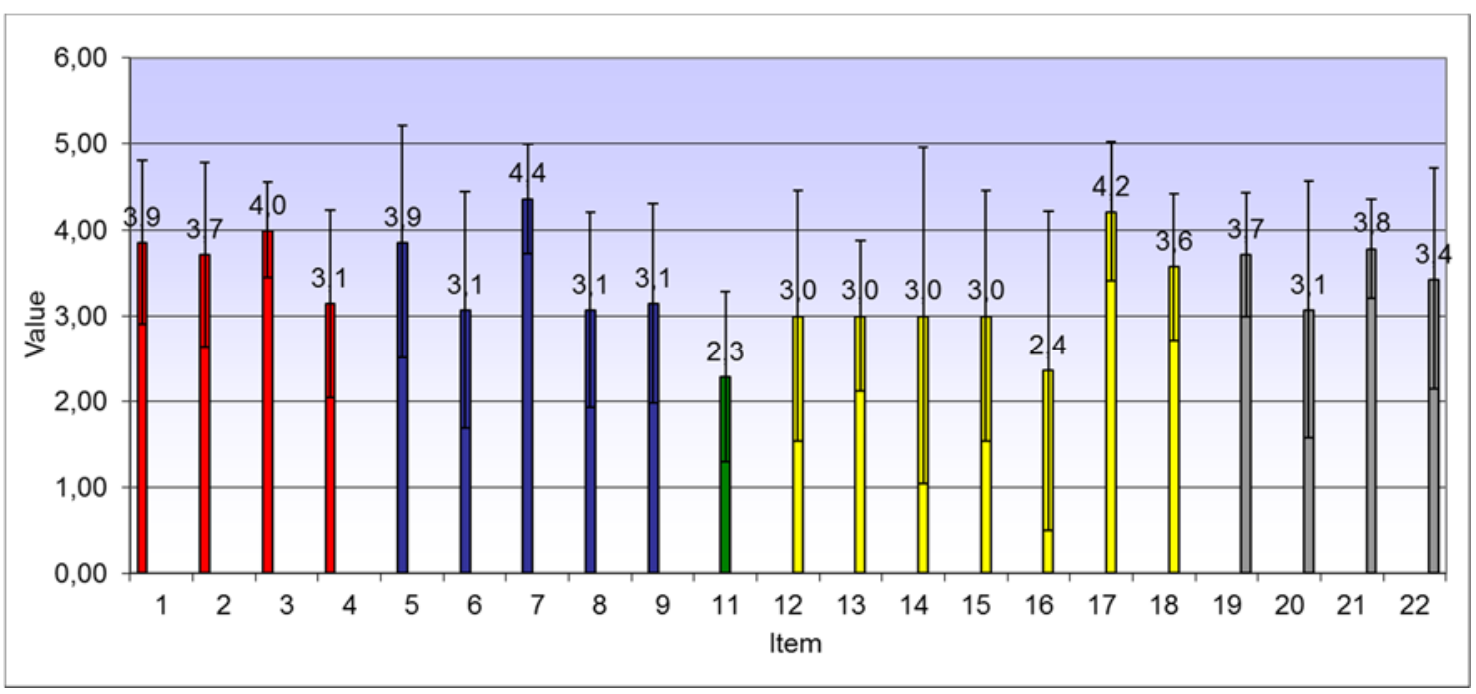

Figure 4: Survey results

For the sake of clarity, item 10, which assess the student's dedication to the pilot CDA, is not represented in the figure. The instructors had foreseen the student would spend about 36 hours, which is almost a perfect match with the mean value.

In the open-ended question (item 23) students expressed repeatedly four major ideas that are summarised next, including one literal students' comment for illustrating each idea:

- More control sessions: Students asked for more control sessions in order to put in common their ideas and queries. Although the forum was available and each team had a personal tutor, they found better the control session because they could brainstorm with both other students and instructors.

"More guidance from instructors had been desirable because if you left the students on their own, we waste a lot of time trying to figure out what to do next."

- Huge workload and low recognition: Although the average of hours spent by the students in developing this pilot CDA was close to the instructors' expectations, 
some groups spent almost a half more. For this reason, they complained that the pilot CDA only graded the $20 \%$ of the total mark. They also pointed out that in a regular semester, they had to attend to five courses at the same time and develop different activities in all these courses similar to this one. Thus, they had to face a huge workload that forces them to withdraw from one or two courses.

"This is a cool activity and you learn a lot with it. However, in the end you do not pass the course with it, which is what we are looking for, and you have to spend a lot of hours completing it. For these reasons, I think it is too much work."

- Computer tools are not enough: Students usually demanded more training on commercial software and less theoretical lessons. Nevertheless, they realised with the pilot CDA that it is more important to know the theoretical concepts rather than to use the commercial software in order to be able to interpret the results of the software.

"I always thought that a good knowledge of software tools will give me a good starting point to face real problems. However, I have realised that this is not good enough because you have to be able to formulate properly the problem, and, after that, you can use the software."

- Good activity: Despite their complaints, they most agreed on the same idea: this pilot CDA got them closer to a real problem and they found it motivating. "These kinds of activities are found appealing and motivating for a Mechanical Engineering student. We should be faced with more activities like these and not going in depth with sided-courses that will be enough completed with just a simple background." 


\section{Discussion: Findings and shortcomings of the pilot CDA}

\subsection{Findings}

Having in mind that the meta-idea described in section 1 is the ultimate goal of this work, in this section our findings of the pilot CDA with respect to the PCDAOs fulfilment and its contribution to the MOs are discussed, as well as the suitability of the PjBL for the achievement of the PCDAOs.

PCDAO 1: To face ill-structured problems. The pilot CDA has been conceived to not just do the math, so this aim is fulfilled by definition and, by extension, has contributed to the MO1. Also, the student's comments summarized in subsection 4.2, especially the las two ('Computer tools are not enough' and 'Good activity') and show that a positive perception about the fulfilment of this objective. Also, items 5, 7 and 22 of the survey prove that students' perception about facing ill-structured problems initially generates some lack of self-confidence that was partially coped with the pilot CDA.

PCDAO 2: To encourage them to participate in student competitions. Although this question was explicitly addressed in the survey (item 2), three students that participated in the pilot CDA joined the team that took part in the Motostudent competition two years later.

PCDAO 3: To be able to identify and distinguish different possibilities of rear suspension designs. The fulfilment of this goal was assessed mainly in the report and in the oral presentation. The groups presented different mechanisms for the suspension system and developed their own design criteria according to the literature review. Grades of the pilot CDA show that students did learn about suspension systems.

PCDAO 4: To improve their skills on searching information, technical vocabulary and collaborative work. This aim is directly related with MO2 (general 
competences) and was mainly assessed using the survey. As can be seen, students' perception about their own work is better than the other members of their team (items 12-16).

Regarding to the MOs, Pilot CDA contributes clearly to MO3 as can be seen on the student's comments, the participation and on the survey. However, as item 4 of the survey shows, one single pilot CDA is not enough to link different courses of the degree.

Additionally, the students' inputs about the pilot CDA will be taken into account in the future. Thus, it is foreseen to increase the percentage of grade of these kinds of activities and also the number of control sessions, including at least two during the semester. We do not convert the pilot CDA in a fully-guided activity, but according to this pilot CDA we think that one more control session would benefit the students' development of the pilot CDA.

The election of PjBL method for the pilot CDA has contributed to the achievement of the aforementioned PCDAOs and MOs, due to its characteristics that we mentioned in section 2.2. Thus, students have improved their general competences and have applied their previous knowledge on Mechanics and Mechanism Science acquired during the LBT sessions to a practical situation, as the design of a motorbike suspension system. It has been demonstrated demonstrated both objectively and subjectively by means of the grading and the survey respectively.

\subsection{Shortcomings}

We have also noticed some shortcomings of the pilot CDA which are worth mentioning. In section 2.2, the increment in the workload of students when learningbased methods are used were pointed out. Furthermore, this pilot CDA considerably increases also the workload of instructors, in terms of design and coordination with both 
other instructors and colleagues. In our opinion, before considering to include activities such as the pilot CDA, this increment in the workload of the instructors must be taking into account in the academic planning.

Another drawback was that only twenty-three followed it and took part in the tests, although forty five students were enrolled in the course. This issue can be surprising to the reader, but the fact is that it is not as unusual as it should be. This was the first edition of this learning-oriented pilot CDA within the course. Students come from lectured-based courses and they usually do not follow all courses they are enrolled.

\section{Conclusions and recommendations}

This paper presents and develops a meta-idea that consists on using a student design competition as an academic tool in the Mechanical Engineering Degree for bringing together all the courses involved under a common framework, enhancing the general competences and motivation of the students and transferring theoretical knowledge to practical situations. This meta-idea is an added value that the in-person universities must offer to their students as a consequence of the Bologna process and the raising of open online resources for self-learning.

However, as this is an ambitious project to carry on, in this paper the pilot CDA that constitute the viability test of the meta-idea is fully described, assessed and discussed. Our findings has demonstrated objectively and subjectively that this particular pilot CDA, has enhanced the general and specific competences, learning outcomes and their motivation for facing a real problem, but it is not enough to establish a link between the courses of the Degree.

We are planning to keep on implementing more CDAs using learning-based methods in other courses such as Applied Mechanics, Dynamics and Machine Design with the redesign components of the motorbike as the main topic. This should help 
students to establish stronger links between different courses and continue working on their competences. We will take into account the students' suggestions in the incoming activities, in order to improve them.

Finally, we would like to make some recommendations in case the reader is inspired by our work and decides to develop a similar experience to the pilot CDA. All activities that are intended to develop and enhance competences or skills, regardless general o specific, must be assessed. As can be seen in the literature, there are lots of instruments that can be used for evaluation and have demonstrated to be useful. Having this in mind, however, we recommend to mark the activity related with the design competition up to $30 \%$ of the total mark initially. Also, these activities, although they are essentially motivating, represent a substantial change in the traditional LBT. When this pilot CDA is being settled during the years and future students know in advance that they have to face this pilot CDA, the relative weight could be increased or even take over the approach of the course. Moreover, the increment of the workload of both students and instructors must be foreseen and taken into account when designing these kinds of activities.

\section{Annex 1: Statement of work}

This pilot CDA aims to redesign kinematically the rear suspension system of the race motorbike which took part in the MotoStudent competition. Students must report the redesign and must be presented to the instructors and the rest of students in a public session.

Students are expected to achieve next learning outcomes with this project:

- To be able to identify and distinguish different designs of rear suspension systems in motorbikes. 
- To improve their skills in terms of:

o Searching for information.

o Work group.

o Technical language.

- To apply engineering software tools.

- To realize that they are able to face this ill-conditioned and open-ended problems, even if they think they cannot at the beginning.

Students must apply their acquired specific competences during the regular sessions in the classroom and laboratory and will work and improve specifically next general competences:

- GC3: Development of critical thinking.

- GC4: To acquire the ability of verbal communication.

- GC5: To acquire the ability of written communication.

Students are provided with dimensions and dynamic data of the motorbike, as it can be seen below: 


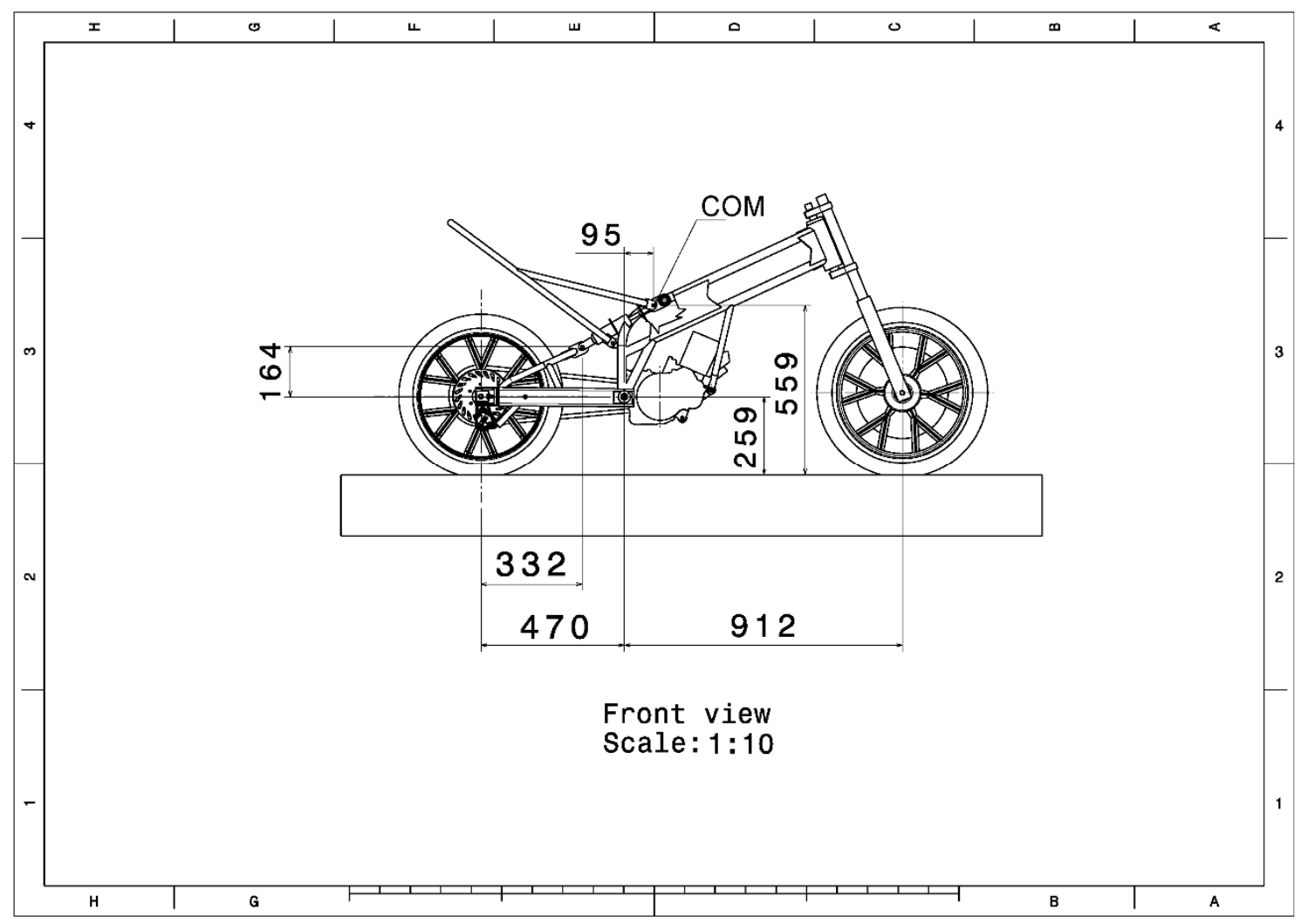

Figure 5: Dimensions of the motorbike

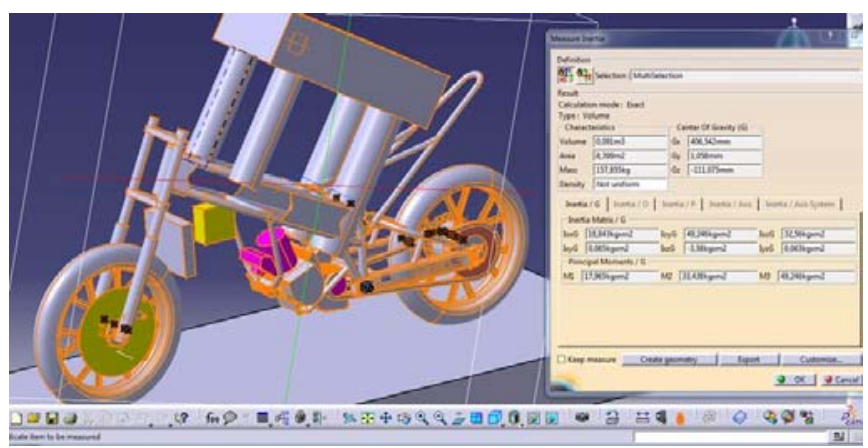

\begin{tabular}{|l|l|}
\hline Property & Value \\
\hline Mass $[\mathrm{kg}]$ & 157,855 \\
\hline Center of gravity $[\mathrm{mm}]$ & 406,$542 ; 1,058 ;-111,075$ \\
\hline Inertia $\mathrm{I}_{\mathrm{oxG}} ; \mathrm{I}_{\mathrm{oyG}} ; \mathrm{I}_{\mathrm{ozG}}\left[\mathrm{kg} \mathrm{m}^{2}\right]$ & 18,$843 ; 49,246 ; 32,56$ \\
\hline Inertia $\mathrm{I}_{\mathrm{xyG}} ; \mathrm{I}_{\mathrm{xzG}} ; \mathrm{I}_{\mathrm{yzG}}\left[\mathrm{kg} \mathrm{m}^{2}\right]$ & 0,$085 ;-3,58 ; 0,063$ \\
\hline
\end{tabular}

Figure 6: Dynamic data of the motorbike

The final report will cover, at least, next main sections. You can include also additional sections, if you consider it necessary. If you fulfil with the description given below, you will be awarded with the maximum grade for each one. 
- Introduction: The report should start with a brief state-of-art description, including the most common mechanisms used currently

- Mechanism proposed: Describe kinematic chain, identifying univocally elements and joints, including a brief description and a sketch with dimensions of each element.

- Description of design: You must describe the design criteria that you have consider. As a result of your design, you must show a chart representing the vertical displacement of the wheel centre vs. spring force.

- Conclusions: You should describe the major difficulties you had to deal with during the development of the project and how you finally coped with them. Comment also if you think that this is a worthy learning activity.

Also, clarity of the written report will be taken into account in the final mark. 
Annex 2: Rubric

\begin{tabular}{|c|c|c|c|c|c|}
\hline Category & 4 & 3 & 2 & 1 & 0 \\
\hline 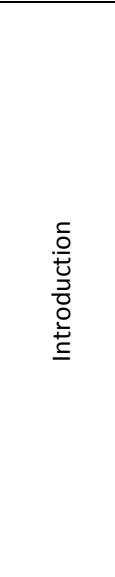 & $\begin{array}{l}\text { The report includes } \\
\text { a review of the } \\
\text { state-of-art of the } \\
\text { most common } \\
\text { mechanisms used. } \\
\text { The references are } \\
\text { reliable and } \\
\text { assorted. The } \\
\text { information is } \\
\text { relevant and } \\
\text { current, and is } \\
\text { presented in a } \\
\text { proper style and } \\
\text { extension. }\end{array}$ & $\begin{array}{l}\text { The report includes } \\
\text { a review of the } \\
\text { state-of-art of the } \\
\text { most common } \\
\text { mechanisms used. } \\
\text { Most of the } \\
\text { references are } \\
\text { reliable and } \\
\text { assorted. Most of } \\
\text { the information is } \\
\text { relevant and } \\
\text { current, although is } \\
\text { presented in a } \\
\text { proper style and } \\
\text { extension. }\end{array}$ & $\begin{array}{l}\text { The report includes } \\
\text { a review of the } \\
\text { state-of-art of the } \\
\text { most common } \\
\text { mechanisms used. } \\
\text { Few references are } \\
\text { reliable and } \\
\text { assorted. Most of } \\
\text { the information is } \\
\text { not relevant and } \\
\text { current, although is } \\
\text { presented in a } \\
\text { proper style and } \\
\text { extension. }\end{array}$ & $\begin{array}{l}\text { The report } \\
\text { includes a review } \\
\text { of the state-of- } \\
\text { art of a few } \\
\text { mechanisms } \\
\text { used. Few } \\
\text { references are } \\
\text { reliable and } \\
\text { assorted. Most } \\
\text { of the } \\
\text { information is } \\
\text { not relevant and } \\
\text { current, although } \\
\text { is mostly } \\
\text { presented in a } \\
\text { proper style and } \\
\text { extension. }\end{array}$ & $\begin{array}{l}\text { This section is } \\
\text { missing in the } \\
\text { report or the } \\
\text { references are } \\
\text { neither reliable nor } \\
\text { assorted. The } \\
\text { information is not } \\
\text { relevant and } \\
\text { current, and is not } \\
\text { presented in a } \\
\text { proper style and } \\
\text { extension. }\end{array}$ \\
\hline 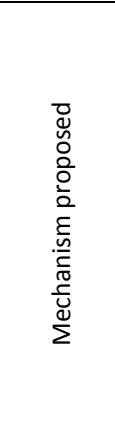 & $\begin{array}{l}\text { The kinematic chain } \\
\text { is correctly } \\
\text { described, } \\
\text { identifying } \\
\text { univocally elements } \\
\text { and joints, including } \\
\text { a brief description } \\
\text { and a sketch with } \\
\text { dimensions of each } \\
\text { element. The } \\
\text { election of the } \\
\text { mechanism is clearly } \\
\text { justified. }\end{array}$ & $\begin{array}{l}\text { The kinematic chain } \\
\text { is correctly } \\
\text { described, } \\
\text { identifying } \\
\text { univocally elements } \\
\text { and joints, including } \\
\text { a brief description } \\
\text { and a sketch with } \\
\text { dimensions of each } \\
\text { element. The } \\
\text { election of the } \\
\text { mechanism is not } \\
\text { justified. }\end{array}$ & $\begin{array}{l}\text { The kinematic chain } \\
\text { is described, } \\
\text { identifying most of } \\
\text { the elements and } \\
\text { joints, including a } \\
\text { brief description and } \\
\text { a sketch with } \\
\text { dimensions of most } \\
\text { element. The } \\
\text { election of the } \\
\text { mechanism is not } \\
\text { justified. }\end{array}$ & $\begin{array}{l}\text { The kinematic } \\
\text { chain is } \\
\text { described, } \\
\text { identifying few } \\
\text { elements and } \\
\text { joints. The } \\
\text { election of the } \\
\text { mechanism is } \\
\text { not justified. }\end{array}$ & $\begin{array}{l}\text { The kinematic chain } \\
\text { is not properly } \\
\text { described. The } \\
\text { election of the } \\
\text { mechanism is not } \\
\text { justified. }\end{array}$ \\
\hline 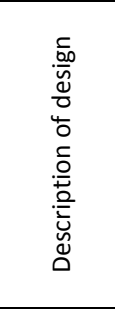 & $\begin{array}{l}\text { The design criteria is } \\
\text { clearly described } \\
\text { and justified. A chart } \\
\text { representing the } \\
\text { vertical } \\
\text { displacement of the } \\
\text { wheel centre vs. } \\
\text { spring force is also } \\
\text { included. }\end{array}$ & $\begin{array}{l}\text { The design criteria is } \\
\text { clearly described but } \\
\text { not justified. A chart } \\
\text { representing the } \\
\text { vertical } \\
\text { displacement of the } \\
\text { wheel centre vs. } \\
\text { spring force is also } \\
\text { included. }\end{array}$ & $\begin{array}{l}\text { The design criteria is } \\
\text { vaguely described } \\
\text { and not justified. A } \\
\text { chart representing } \\
\text { the vertical } \\
\text { displacement of the } \\
\text { wheel centre vs. } \\
\text { spring force is } \\
\text { included. }\end{array}$ & $\begin{array}{l}\text { The design } \\
\text { criteria is vaguely } \\
\text { described and } \\
\text { not justified. }\end{array}$ & $\begin{array}{l}\text { The design criteria is } \\
\text { neither described } \\
\text { not justified. A chart } \\
\text { representing the } \\
\text { vertical } \\
\text { displacement of the } \\
\text { wheel centre vs. } \\
\text { spring force is not } \\
\text { included. }\end{array}$ \\
\hline 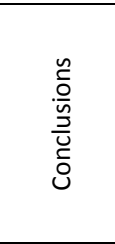 & $\begin{array}{l}\text { Conclusions are } \\
\text { briefly and clearly } \\
\text { summarized. } \\
\text { Constructive } \\
\text { commentaries about } \\
\text { if this is a worthy } \\
\text { learning. }\end{array}$ & $\begin{array}{l}\text { Conclusions are } \\
\text { included. } \\
\text { Commentaries } \\
\text { about if this is a } \\
\text { worthy learning. }\end{array}$ & $\begin{array}{l}\text { Conclusions are } \\
\text { hardly included. } \\
\text { Commentaries } \\
\text { about if this is a } \\
\text { worthy learning. }\end{array}$ & $\begin{array}{l}\text { Conclusions are } \\
\text { hardly included } \\
\text { and difficult to } \\
\text { distinguish from } \\
\text { the other } \\
\text { sections. }\end{array}$ & $\begin{array}{l}\text { This section is } \\
\text { missing in the } \\
\text { report or does not } \\
\text { have the proper } \\
\text { contents described } \\
\text { in the statement of } \\
\text { the problem. }\end{array}$ \\
\hline
\end{tabular}

Additional category for report

\begin{tabular}{|c|c|c|c|c|c|}
\hline Category & 4 & 3 & 2 & 1 & 0 \\
\hline 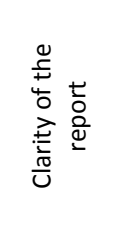 & $\begin{array}{l}\text { Writer makes no } \\
\text { errors in grammar, } \\
\text { spelling, } \\
\text { capitalization or } \\
\text { punctuation that } \\
\text { distract the reader } \\
\text { from the content. }\end{array}$ & $\begin{array}{l}\text { Writer makes } 1-2 \\
\text { errors in grammar, } \\
\text { spelling, } \\
\text { capitalization or } \\
\text { punctuation that } \\
\text { distract the reader } \\
\text { from the content. }\end{array}$ & $\begin{array}{l}\text { Writer makes 3-4 } \\
\text { errors in grammar, } \\
\text { spelling, } \\
\text { capitalization or } \\
\text { punctuation that } \\
\text { distract the reader } \\
\text { from the content. }\end{array}$ & $\begin{array}{l}\text { Writer makes 5-6 } \\
\text { errors in grammar, } \\
\text { spelling, } \\
\text { capitalization or } \\
\text { punctuation that } \\
\text { distract the reader } \\
\text { from the content. }\end{array}$ & $\begin{array}{l}\text { Writer makes more } \\
\text { than } 6 \text { errors in } \\
\text { grammar, spelling, } \\
\text { capitalization or } \\
\text { punctuation that } \\
\text { distract the reader } \\
\text { from the content. }\end{array}$ \\
\hline
\end{tabular}

Additional category for oral presentation

\begin{tabular}{|c|c|c|c|c|c|}
\hline Category & 4 & 3 & 2 & 1 & 0 \\
\hline 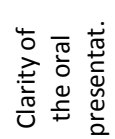 & $\begin{array}{l}\text { Speaker shows a full } \\
\text { understanding of } \\
\text { the topic. }\end{array}$ & $\begin{array}{l}\text { Speaker shows a } \\
\text { good understanding } \\
\text { of the topic. }\end{array}$ & $\begin{array}{l}\text { Speaker shows a } \\
\text { good understanding } \\
\text { of parts of the topic. }\end{array}$ & $\begin{array}{l}\text { Speaker shows } \\
\text { difficulties to } \\
\text { understand most } \\
\text { parts of the topic. }\end{array}$ & $\begin{array}{l}\text { Speaker does not } \\
\text { seem to understand } \\
\text { the topic at all. }\end{array}$ \\
\hline
\end{tabular}




\section{References}

Ahlgren, D. J., \& Verner, I. M. (2013). Socially responsible engineering education through assistive robotics projects: The RoboWaiter competition. International Journal of Social Robotics, 5(1), 127-138.

Al-Marzouqi, M., \& El-Naas, M. H. (2012). The role of environmental design competitions in engineering education. International Journal of Engineering Education, 28(4), 959-965.

Battisti, F., Boato, G., Carli, M., \& Neri, A. (2011). Teaching multimedia data protection through an international online competition. IEEE Transactions on Education, 54(3), 381-386.

Belland, B. R., French, B. F., \& Ertmer, P. A. (2009). Validity and problem-based learning research: A review of instruments used to assess intended learning outcomes. Interdisciplinary Journal of Problem-Based Learning, 3(1).

Bin Masek, A., \& Bin Yamin, S. (2010). Problem based learning: A review of the monitoring and assessment model. Engineering Education (ICEED), 2010 2nd International Congress on, pp. 171-175.

Carson, S., Kanchanaraksa, S., Gooding, I., Mulder, F., \& Schuwer, R. (2012). Impact of OpenCourseWare publication on higher education participation and student recruitment. International Review of Research in Open and Distance Learning, 13(4), 19-32.

Davies, H. C. (2013a). Formula student as part of a mechanical engineering curriculum. European Journal of Engineering Education, 38(5), 485-496.

Davies, H. C. (2013b). Integrating a multi-university design competition into a mechanical engineering design curriculum using modern design pedagogy. Journal of Engineering Design, 24(5), 383-396.

European Commission. (2009). ECTS users' guide. (). doi:10.2766/88064

European Ministers of Education. (1999). The Bologna declaration

Formula SAE series. Retrieved August, 2015, from http://students.sae.org/cds/formulaseries/

Galand, B., Frenay, M., \& Raucent, B. (2012). Effectiveness of problem-based learning in engineering education: A comparative study on three levels of knowledge structure. International Journal of Engineering Education, 28(4), 939-947. 
Gil, P., Candelas, F. A., García, G. J., \& Jara, C. A. (2012). Open educational resources: The role of OCW, blogs, and videos in computer networks classroom. International Journal of Emerging Technologies in Learning, 7(3), 4-10.

Giralt, F., Herrero, J., Grau, F. X., Alabart, J. R., \& Medir, M. (2000). Two way integration of engineering education through a design project. Journal of Engineering Education, 89(2), 219-229.

Jimenez, G., Pardo, J. J., Minguez, E., \& Cuervo, D. (2015). Educational initiatives to develop transversal skills in the nuclear engineering subjects at universidad politécnica de madrid. The International Journal of Engineering Education, 31(1), 229; 229-237.

Jonassen, D., Strobel, J., \& Lee, C. B. (2006). Everyday problem solving in engineering: Lessons for engineering educators. Journal of Engineering Education, 95(2), 139-151.

Labossìre, P., \& Bisby, L. A. (2010). Lessons learned from a design competition for structural engineering students: The case of a pedestrian walkway at the Université de Sherbrooke. Journal of Professional Issues in Engineering Education and Practice, 136(1), 48-56.

Lee, M. M., Lin, M. -. G., \& Bonk, C. J. (2007). OOPS, turning MIT OpenCourseWare into Chinese: An analysis of a community of practice of global translators. International Review of Research in Open and Distance Learning, 8(3)

Lerman, S., \& Potts, J. P. (2006). Unlocking knowledge, empowering minds: MIT's OpenCourseWare project. IEEE Signal Processing Magazine, 23(5), 11-15.

Martin, F. G. (2012). Education will massive open online courses change how we teach. Communications of the ACM, 55(8), 26-28.

Maseda, F. J., Martija, I., \& Martija, I. (2012). A training tool and methodology to allow concurrent multidisciplinary experimental projects in engineering education. IEEE Transactions on Education, 55(3), 357-364.

MotoStudent. Retrieved August, 2015, from http://www.motostudent.com/

Nepal, K. P. (2013). Comparative evaluation of PBL and traditional lecture-based teaching in undergraduate engineering courses: Evidence from controlled learning environment. International Journal of Engineering Education, 29(1), $17-22$. 
OECD. (2011). A tuning-AHELO conceptual framework of expected desired/learning outcomes in engineering. (No. 60). OECD Publishing.

Post, M. A., \& Lee, R. (2011). Lessons learned from the York University Rover Team (YURT) at the university rover challenge 20082009. Acta Astronautica, 68(7-8), 1343-1352.

Prados, J. W., Peterson, G. D., \& Lattuca, L. R. (2005). Quality assurance of engineering education through accreditation: The impact of engineering criteria 2000 and its global influence. Journal of Engineering Education, 94(1), 165183.

Prince, M. J., \& Felder, R. M. (2006). Inductive teaching and learning methods: Definitions, comparisons, and research bases. Journal of Engineering Education, 95, 123-138.

RoboCup. Retrieved August, 2015, from http://www.robocup.org/about-robocup/objective/

Shell eco-marathon. Retrieved August, 2015, from http://www.shell.com/global/environment-society/ecomarathon.html

Stolk, J. D. (2015). Can disciplinary integration promote students' lifelong learning attitudes and skills in project-based engineering courses? The International Journal of Engineering Education, 31(1), 434-449.

Tao, J., Zhang, S., Yuan, Y., \& Wen, X. (2015). Extending engineering specialty course concepts in electrical engineering education. International Journal of Electrical Engineering Education, 52(1), 39-51.

Vlădoiu, M. (2011). State-of-the-art in open courseware initiatives worldwide. Informatics in Education, 10(2), 271-294.

Woods, D. R. (1996). Problem-based Learning: helping your students gain the most from PBL. Retrieved October, 2014, from http://chemeng.mcmaster.ca/problembased-learning.

Yadav, A., Shaver, G. M., \& Meckl, P. (2010). Lessons learned: Implementing the case teaching method in a mechanical engineering course. Journal of Engineering Education, 99(1), 55-64.

Yadav, A., Subedi, D., Lundeberg, M. A., \& Bunting, C. F. (2011). Problem-based learning: Influence on students' learning in an electrical engineering course. Journal of Engineering Education, 100(2), 253-280.

Zhou, C., \& Kolmos, A. (2013). Interplay between individual creativity and group creativity in problem and project-based learning (PBL) environment in 
engineering education. International Journal of Engineering Education, 29(4), 866-878. 